\title{
Respiratory outcomes of late preterm infants of mothers with early and late onset preeclampsia
}

\author{
Yasser Soliman ${ }^{1} \cdot$ Belal Alshaikh ${ }^{2} \cdot$ Essa Alawad $^{2} \cdot$ Albert Akierman $^{2} \cdot$ Adel Elsharkawy $^{2} \cdot$ Kamran Yusuf $^{2}$
}

Received: 21 January 2019 / Revised: 2 July 2019 / Accepted: 1 August 2019 / Published online: 24 September 2019

(c) The Author(s), under exclusive licence to Springer Nature America, Inc. 2019

\begin{abstract}
Objective To study the effect of early and late onset preeclampsia (EOPE, LOPE, respectively) on outcomes of late preterm infants.

Study design Cohort study of late preterm infants admitted to a tertiary care NICU from January 2014-July 2015. Outcomes of late preterm infants of EOPE mothers were compared with the next late preterm infant of a LOPE mother and the next two late preterm infants of normotensive non-PE mothers. Primary outcome comprised use of continuous positive airway pressure, mechanical ventilation and/or surfactant in the $24 \mathrm{~h}$ after birth.

Results Compared to normotensives $(n=131)$, adjusted odds ratio (AORs) of the primary outcome was higher in the EOPE $(n=64)$ and LOPE $(n=65)$ groups but reached statistical significance only in the EOPE group, AORs $12.9,95 \%$ CI 3.5-37 and $2.7,95 \%$ CI $0.95-8.1$, respectively.

Conclusions Compared to late preterm infants of normotensive and LOPE mothers, infants of mothers with EOPE have significantly higher respiratory morbidity.
\end{abstract}

\section{Introduction}

Late preterm infants, defined as births between $34^{+0}$ and $36^{+6}$ weeks gestation, constitute the largest proportion of preterm births, being $85 \%$ in Canada [1-3]. There is significant morbidity associated with late preterm birth with respiratory distress syndrome (RDS) and transient tachypnea of the newborn (TTNB) the commonest $[4,5]$. Compared with term infants, late preterm infants are nine times more likely to be placed on continuous positive airway pressure (CPAP), five times more likely to be placed on mechanical ventilation and forty two times more likely to need surfactant replacement [6]. The cost associated with the care of late preterm infants is substantial, corresponding to more than 208 million dollars annually in Canada [7].

Kamran Yusuf

kyusuf@ucalgary.ca

1 Division of Neonatology, Department of Pediatrics, The Hospital for Sick Children, University Avenue, Toronto, ON M5G 1X8, Canada

2 Section of Neonatology, Department of Pediatrics, Cumming School of Medicine, University of Calgary, Calgary, AB, Canada
Initial studies on morbidity in late preterm births compared outcomes to term births without taking into account underlying maternal medical conditions that may lead to preterm birth. This is now being questioned with the realization that in addition to prematurity per se, maternal conditions also contribute to morbidity in late preterm infants $[8,9]$. One such condition is preeclampsia.

Preeclampsia is a pregnancy specific disorder characterized by hypertension and proteinuria manifesting at or after twenty weeks of gestation and is a major cause of maternal and neonatal mortality and morbidity worldwide [10]. Although placental dysfunction is a hallmark of preeclampsia, the disorder is heterogeneous [10]. Based on gestational age at onset of disease, preeclampsia is classified as early, occurring before 34 weeks gestation and late occurring at or after 34 weeks of gestation [10, 11]. Both have similarities and distinct features. Placental changes are more marked in early onset preeclampsia while maternal factors such as increased body mass index (BMI) and metabolic syndrome play a greater role in late onset disease [12]. Early onset preeclampsia is also associated with a greater adverse impact on maternal and fetal health [13]. Although early onset disease manifests before 34 weeks gestation, a third of women deliver at or after 34 weeks gestation [12, 14]. Surprisingly, reports of the effects 
preeclampsia on outcomes of late preterm infants have not differentiated between early and late onset preeclampsia, despite significant differences between the two. The objective of our study was to investigate the effects of early and late onset preeclampsia on the outcomes of late preterm infants, with the primary objective being respiratory outcomes.

\section{Methods}

The Neonatal Intensive Care Unit (NICU) in Calgary maintains a prospectively collected electronic database of all infants admitted to the NICU. Late preterm infants born between $34^{+0}$ and $36^{+6}$ gestation to a mother with early onset preeclampsia between January 2014 and July 2015 were included in the study. Their outcomes were compared with the next late preterm infant born to a mother with late onset preeclampsia and the next two late preterm infants born to normotensive mothers. A prestructured data form was completed for all infants. In case of missing data, the infant's medical record charts were reviewed. The Conjoint Health Research Ethics Board of the University of Calgary approved the study.

The primary outcome comprised the use of CPAP or mechanical ventilation and/or surfactant use in the first $24 \mathrm{~h}$ after birth. We chose this primary outcome for several reasons. Amongst all the morbidities faced by late preterm infants, respiratory morbidity is the most common. The two most common diagnosis for respiratory distress in late preterm period, RDS and TTNB, can sometimes be difficult to distinguish based on clinical manifestations and chest X-ray [15]. Importantly, similar definition of respiratory morbidity has been used in other large studies [4, 5]. Secondary outcomes included (i) RDS-diagnosed based on signs of respiratory distress, a typical chest X-ray and/or need for surfactant [16]. (ii) TTNB-diagnosed on a chest $\mathrm{X}$-ray showing good volume with increased vascularity and the presence of a transverse fissure [17]. (iii) Use of supplemental oxygen by nasal cannula. (iv) Small for gestational age (SGA)-defined as birthweight below the 10th centile using the Fenton growth charts [18]. (v) Length of hospital stay in days. (vi) Hypoglycemia defined as blood glucose levels $<2.6 \mathrm{mmol} / \mathrm{L}$ (Canadian Pediatric Society Position Statement, available at www.cps.ca). (vii) Number of infants in each group needing phototherapy.

\section{Definitions}

Preeclampsia definition was based on Society of Obstetrics and Gynecology Canada recommendations and was defined as systolic blood pressure $\geq 140 \mathrm{mmHg}$ or a diastolic level of (Korotkoff 5) $\geq 90 \mathrm{mmHg}$ on two or more occasions at least 15 min apart after 20 weeks gestation in a woman with previously normal blood pressure. Proteinuria was defined as $\geq 0.3 \mathrm{~g}$ protein in a $24 \mathrm{~h}$ urine sample. When a $24 \mathrm{~h}$ urinary sample was not feasible, or $\geq 30 \mathrm{mg} / \mathrm{mmol}$ urinary creatinine in a spot urine sample or $\geq 1+$ on a urinary dipstick test-strip was used as criteria for proteinuria [19]. Early onset preeclampsia was onset of symptoms at $<34$ weeks gestation and late onset preeclampsia onset of symptoms $\geq 34$ weeks gestation. Histological chorioamnionitis was defined as infiltration of polymorphonuclear leukocytes in the fetal membranes and chorionic plate, and funisitis as the presence of these cells in the umbilical cord blood vessel walls and Wharton's jelly [20]. Antenatal steroids were considered a course if more than twelve hours had elapsed after the first dose [21]. Diabetes included both gestational and pregestational forms of the disease. Gestational age was based on a first trimester ultrasound and date of embryo transfer in cases of in vitro fertilization. Surfactant was administered when oxygen requirements were persistently $>30 \%$. Exclusion criteria included infants born with any congenital malformations or chromosomal anomalies, infants of mothers with chronic hypertension (onset before 20 weeks of gestation), maternal renal, cardiovascular, endocrine or autoimmune disease, substance abuse, and TORCH infections. Women who did not have a first trimester ultrasound were also excluded.

\section{Statistics}

As the distribution of the relevant variables was not normal, we chose conservative nonparametric analysis for continuous variables, using the Kruskal-Wallis test. Categorical variables were compared using the $\chi^{2}$ or Fisher's exact test as appropriate. Bonferroni correction was used post hoc for multiple comparisons. To identify risk factors for development of the primary outcome, multivariable ordered logistic regression with backward elimination approach was performed. Any risk factors that demonstrated associations, whether statistically significant or judged to be clinically significant, with both preeclampsia and the primary outcome but were not intermediate variables, were included in the modeling process as possible confounders [22]. The least significant variables were then removed until all remaining variables were significant at $P$ value of 0.2 . The $P$ value of 0.2 was set conservatively as an entry for variables to proceed to the next step in the analysis [23]. The adjusted odds ratio (OR) and their 95\% confidence interval (CI) are reported. A $P<0.05$ was considered significant. Data were analyzed using STATA v. 13 (College Station, Texas, USA).

\section{Results}

During the study period, there were 1760 admissions to the NICU. Amongst the 67 women with early onset 
preeclampsia, four women with chronic hypertension and two with a history of substance abuse were excluded. There were three sets of twins in the group resulting in 64 infants eligible for the study. Of the 68 women with late onset preeclampsia, two women with substance abuse and one with chronic hypertension were excluded. There were no twins in the group resulting in 65 infants eligible for the study. One hundred and thirty three normotensive women who delivered late preterm infants between 34 and 36 weeks gestation were included as controls. On chart review, four of these women had a history of substance abuse, two had chronic hypertension and one each had systemic lupus erythematosus and antiphospholipid syndrome. They were excluded from the study. There were six sets of twins in the group resulting in 131 infants eligible for the study (Fig. 1).

Table 1 shows the maternal and neonatal demographic variables between the three groups. There was no difference in the maternal age, diabetes, twins, chorioamnionitis, smoking, number of male infants and Apgar scores $<7$ at 5 min between the three groups. Compared to the normotensive group, the number of primigravida mothers was
Fig. 1 Flow diagram of patients included in the study

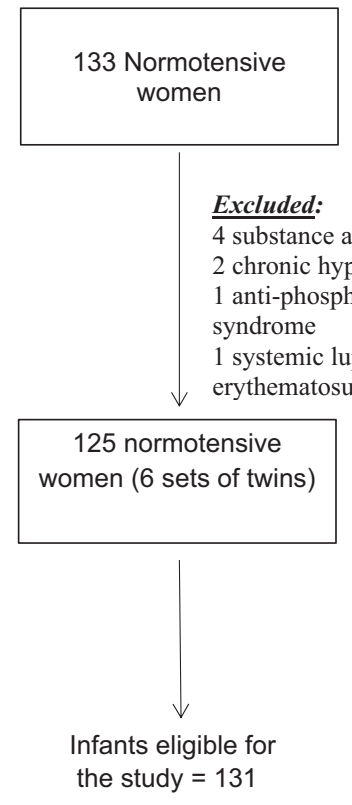

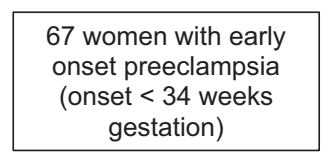



Excluded:

4 chronic hypertension

2 substance abuse

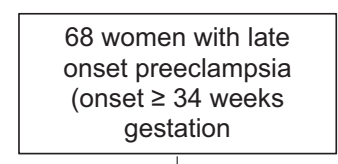

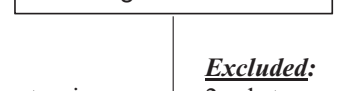

Excluded:

1 chronic hypertension

Table 1 Maternal and neonatal demographics

\begin{tabular}{|c|c|c|c|c|}
\hline & $\begin{array}{l}\text { Normotensive } \\
N=131\end{array}$ & $\begin{array}{l}\text { Early onset preeclampsia } \\
N=64\end{array}$ & $\begin{array}{l}\text { Late onset preeclampsia } \\
N=65\end{array}$ & $P$-value \\
\hline Maternal age (years) & $31(28-35)$ & $32(27-38)$ & $34(30-35)$ & 0.15 \\
\hline Primigravida $n(\%)$ & $54(41)$ & $31(48)$ & $35(53)$ & 0.19 \\
\hline Gestation (weeks) & $35(35-35)$ & $34(34-35)$ & $35(35-36)$ & $0.00^{\mathrm{a}, \mathrm{c}}$ \\
\hline Birthweight (g) & $2450(2216-2450)$ & $2036(1698-2515)$ & $2290(210-2675)$ & $0.00^{\mathrm{c}}$ \\
\hline Diabetes $n(\%)$ & $24(18)$ & $10(16)$ & $11(17)$ & 0.89 \\
\hline Antenatal steroids $n(\%)$ & $14(11)$ & $34(53)$ & $4(6)$ & $0.00^{\mathrm{a}, \mathrm{b}, \mathrm{c}}$ \\
\hline Twins $n(\%)$ & $8(6)$ & $3(5)$ & 0 & 0.13 \\
\hline Chorioamnionitis $n(\%)$ & $14(11)$ & $4(6)$ & $4(6)$ & 0.43 \\
\hline C-section $n(\%)$ & $47(36)$ & $44(69)$ & $26(40)$ & $0.00^{\mathrm{a}, \mathrm{c}}$ \\
\hline Smoking $n(\%)$ & $12(9)$ & $2(3)$ & $4(6)$ & 0.28 \\
\hline Male $n(\%)$ & $84(64)$ & $35(55)$ & $43(66)$ & 0.33 \\
\hline Apgar $<7$ at $1 \min n(\%)$ & $16(12)$ & $28(43)$ & $9(14)$ & $0.00^{\mathrm{a}, \mathrm{c}}$ \\
\hline Apgar $<7$ at $5 \min n(\%)$ & $4(3)$ & $6(9)$ & $3(5)$ & 0.16 \\
\hline
\end{tabular}

${ }^{a}$ Early onset preeclampsia vs. normotensive

${ }^{\mathrm{b}}$ Late onset preeclampsia vs. normotensive

${ }^{c}$ Early onset preeclampsia vs. late onset preeclampsia 
Table 2A Primary outcomeunivariate analysis

\begin{tabular}{lcccc}
\hline & $\begin{array}{l}\text { Normotensive } \\
N=131\end{array}$ & $\begin{array}{l}\text { Early onset preeclampsia } \\
N=64\end{array}$ & $\begin{array}{l}\text { Late onset preeclampsia } \\
N=65\end{array}$ & $P$-value \\
\hline Surfactant $n(\%)$ & $1(0.8)$ & $5(8)$ & $2(3)$ & $0.02^{\mathrm{a}, \mathrm{c}}$ \\
CPAP $n(\%)$ & $10(7)$ & $26(41)$ & $7(11)$ & $0.00^{\mathrm{a}, \mathrm{c}}$ \\
MV $n(\%)$ & $1(0.8)$ & $11(17)$ & $4(6)$ & $0.00^{\mathrm{a}, \mathrm{c}}$ \\
Composite $^{\mathrm{d}} n(\%)$ & $11(8)$ & $37(58)$ & $11(26)$ & $0.00^{\mathrm{a}, \mathrm{c}}$ \\
\hline
\end{tabular}

${ }^{a}$ Early onset preeclampsia vs. normotensive

${ }^{\mathrm{b}}$ Late onset preeclampsia vs. normotensive

${ }^{c}$ Early onset preeclampsia vs. late onset preeclampsia

${ }^{\mathrm{d}}$ Mechanical ventilation (MV) and/or continuous positive airway pressure (CPAP) and/or surfactant use higher in the two preeclamptic groups but the difference did not reach statistical significance. Compared with the other two groups, gestational age was significantly lower in the early onset preeclampsia group. Birthweight was significantly lower and SGA rates significantly higher in the two preeclampsia groups compared with the normotensive group $(P<0.00)$. Antenatal steroid use, $\mathrm{C}$-section rates, and Apgar scores $<7$ at $1 \mathrm{~min}$ were significantly higher in the early onset preeclampsia group.

Table $2 \mathrm{~A}$ shows the univariate analysis of the primary outcome and its components in the three groups. All infants who received surfactant were also placed on mechanical ventilation. The composite outcome as well as the individual components were significantly higher in the early onset preeclampsia group $(P=0.02$ for surfactant and $<0.00$ for the other variables).

Table 2B shows the results of multivariable ordered logistic regression as the odds ratio (ORs) of the primary outcome in early and late onset preeclampsia with the normotensive group as the reference group. The final model included gestation, mode of delivery, sex, antenatal steroids, and small for gestational age. The odds of the primary outcome-CPAP use, mechanical ventilation and/or surfactant use-was greater in the two preeclampsia group with the early onset preeclampsia group having the higher odds. However, the higher odds in the late onset group did not reach statistical significance (OR $12.95 \%$ CI $3.8-37, P=<0.00$ for early onset preeclampsia and OR 2.7 95\% CI 0.94-8.1, $P=0.06$ ).

Table 3 shows the secondary outcomes between the three groups. Compared to the normotensive group, TTNB, nasal cannula oxygen, hypoglycemia, SGA infants and use of phototherapy, duration of hospital stay was higher in the two preeclampsia groups. RDS was significantly higher in the early onset group.

During the study period, there were no deaths in any of the groups. Although infants were placed on anti-biotics for suspected sepsis, none of the infants had a positive blood or cerebrospinal fluid culture.
Table 2B Primary outcome-multivariable analysis

\begin{tabular}{lllll}
\hline & \multicolumn{2}{l}{ Early onset $N=64$} & \multicolumn{2}{l}{ Late onset $N=65$} \\
\hline & OR $(95 \% \mathrm{Cl})$ & $P$-value & OR $(95 \% \mathrm{Cl})$ & $P$-value \\
Composite $^{\mathrm{a}}$ & $13(3.5-37)$ & 0.00 & $2.7(0.94-8.1)$ & 0.06 \\
\hline
\end{tabular}

Respiratory outcomes of late preterm infants of mothers with early and late onset preeclampsia with infants of normotensive mothers as reference group. Adjusted for gestation, mode of delivery, antenatal steroid use, sex, SGA status, diabetes, twins, chorioamnionitis and Apgar score $<7$ at $1 \mathrm{~min}$

$O R$ odds rates, $C I$ confidence intervals

${ }^{a}$ Mechanical ventilation and/or continuous positive airway pressure (CPAP) and/or surfactant use

\section{Discussion}

Our results show that late preterm infants of mothers with preeclampsia have worse respiratory outcomes compared to late preterm infants of normotensive mothers. The outcome is significantly worse in infants of mothers with early onset preeclampsia and persisted after controlling for potential confounders. We also demonstrate that late preterm infants of mothers with preeclampsia also have significantly more non-respiratory morbidity. This is the first study to differentiate between outcomes of late preterm infants of early and late onset preeclampsia.

Studies on the outcomes of late preterm infants of preeclamptic mothers show divergent results with worse outcomes and no difference when compared to late preterm infants of normotensive mothers [9, 24-26]. These conflicting results are, we believe, due to investigators not differentiating between late preterm infants of early and late onset preeclampsia. Gouyon et al., using a large cohort from France, reported higher risk of severe respiratory morbidity, in late preterm infants of mothers with hypertensive disorder of pregnancy [9]. As in our study, severe respiratory morbidity was defined as the need for mechanical ventilation and/or CPAP. Habli et al., in a secondary analysis of 
Table 3 Secondary outcomes

\begin{tabular}{|c|c|c|c|c|}
\hline & $\begin{array}{l}\text { Normotensive } \\
N=131\end{array}$ & $\begin{array}{l}\text { Early onset preeclampsia } \\
N=64\end{array}$ & $\begin{array}{l}\text { Late onset preeclampsia } \\
N=65\end{array}$ & $P$-value \\
\hline $\operatorname{RDS}(n \%)$ & $5(4)$ & $16(25)$ & $4(6)$ & $0.00^{\mathrm{a}, \mathrm{c}}$ \\
\hline TTNB & $19(14.5)$ & $26(41)$ & $13(20)$ & $0.00^{\mathrm{a}}$ \\
\hline Nasal Cannula oxygen & $2(2)$ & $6(10)$ & $4(6)$ & $0.03^{\mathrm{a}}$ \\
\hline Duration of MV (days) $^{\mathrm{d}}$ & 1 & $2(2-3)$ & $1.5(1-2.75)$ & 0.14 \\
\hline Hypoglycemic $(n \%)$ & $18(14)$ & $18(28)$ & $19(28)$ & $0.01^{\mathrm{a}, \mathrm{b}}$ \\
\hline Small for gestational age $(\%)$ & $15(11)$ & $35(54)$ & $24(37)$ & $0.00^{\mathrm{a}, \mathrm{b}}$ \\
\hline Phototherapy (n\%) & $22(17)$ & $39(61)$ & $22(34)$ & $0.00^{\mathrm{a}, \mathrm{c}}$ \\
\hline Hospital stay (days) & $7(5-9)$ & $13(10-17)$ & $8(4-12)$ & $0.00^{\mathrm{a}, \mathrm{c}}$ \\
\hline
\end{tabular}

$R D S$ respiratory distress syndrome, $T T N B$ transient tachypnea of the newborn, $M V$ mechanical ventilation

${ }^{a}$ Early onset preeclampsia vs. normotensive

${ }^{\mathrm{b}}$ Late onset preeclampsia vs. normotensive

${ }^{c}$ Early onset preeclampsia vs. late onset preeclampsia

${ }^{\mathrm{d}}$ One infant in the normotensive group needed mechanical ventilation for 1 day

the Calcium for Preeclampsia Prevention trial, investigated neonatal outcomes of infants born at 35-37 weeks of gestation to hypertensive and normotensive women [24]. Respiratory morbidity, defined by the need for oxygen, CPAP or mechanical ventilation was higher at each gestational age in infants of hypertensive mothers but reached statistical significance only at 37 weeks. Lagenveld et al. compared outcomes of late preterm infants of mothers with preeclampsia, gestational hypertension and normotensive pregnancies in a large cohort from the Netherlands [25]. They found higher rates of hypoglycemia and SGA in the preeclampsia group, results similar to our study. The odds of RDS were lower in the preeclampsia group with no difference in TTNB and need for oxygen. However, the study did not have data on antenatal corticosteroid use, systolic blood pressure was not used in the definition of preeclampsia and $30 \%$ of the cohort was excluded because of missing data. Masoura et al. reported increased rates of hypoglycemia and RDS and lower Apgar scores in late preterm infants of preeclamptic mothers [26]. In a study from Australia, of infants 30-36 weeks gestation, ventilator support was required significantly more in infants of mothers with preeclampsia [27]. As in other studies, no distinction was made between early and late onset preeclampsia.

Our results demonstrate increased TTNB in late preterm infants of both early and late onset preeclampsia and increased RDS in early onset preeclampsia. In addition, the use of surfactant CPAP and mechanical ventilation was higher in late preterm infants of mothers with preeclampsia, with higher rates in infants of mothers with early onset preeclampsia. As primary CPAP is associated with better respiratory outcomes compared with elective intubation, nine of the fifteen infants placed on mechanical ventilation were initially tried on CPAP but had to be intubated because of worsening respiratory status and increasing oxygen requirements [28]. Of these nine patients, six were from the early onset, two from the late onset and one from the normotensive group. Increased respiratory morbidity in preterm infants of mothers with preeclampsia can potentially be explained by the antiangiogenic state in preeclampsia. Several studies have demonstrated higher levels of antiangiogenic factors, soluble vascular endothelial growth factor receptor-1 (sFlt-1) and soluble Endoglin and lower levels of angiogenic factors, vascular endothelial growth factor (VEGF), and placental growth factor in preeclampsia [10, 29-32]. VEGF plays a key role in lung vascular development, which promotes alveolar growth, and also enhances surfactant protein production [33,34]. In animal models, VEGF prevents RDS and higher levels of sFlt1 and lower levels of VEGF are described in more severe RDS [35-37]. Importantly, this antiangiogenic state is much more pronounced in early onset preeclampsia with levels of sFlt much higher and levels of VEGF much lower in early onset preeclampsia as compared with late onset preeclampsia [38, 39]. In addition, in early onset preeclampsia the fetus is exposed to the hostile intrauterine antiangiogenic environment for a longer period. These factors may be responsible for the worse respiratory outcomes in late preterm infants of mothers with early onset preelampsia as compared with infants of mothers with late onset preeclamsia and normotensive mothers. A negative correlation between sFlt1 levels and birthweight is reported in preeclampsia, with higher sFlt1 levels associated with lower birthweight $[38,40]$. In our cohort, the lower birthweight in infants of preeclamptic mothers, more marked in the early onset group, can conceivably be attributed to this negative correlation. 
The composite outcome of CPAP and/or mechanical ventilation use in the normotensive group in our cohort was $8 \%$, similar to the reports by Habli et al. and Gouyon where it was $9.5 \%$ and $8 \%$, respectively $[9,24]$. The rate of CPAP and/or mechanical ventilation use was higher in the preeclamptic group in our cohort compared to the study by Habli et al. (37 vs. $19 \%$ ). However, their cohort included both preeclampsia and gestational hypertension which is a less severe disease associated with less respiratory morbidity, diluting the number of infants needing CPAP or mechanical ventilation.

Antenatal steroid use was $11 \%$ in our normotensive cohort and $20 \%(52 / 260)$ in the entire cohort. These mothers had received steroids for threatened preterm labor before 34 weeks gestation. Although no study has reported on the antenatal steroid use in late preterm infants of early and late onset preeclamptic mothers, Suga et al. and Gymanfi-Bannerman et al. reported rates of $15.2 \%$ and $9.2 \%$, respectively, in late preterm infants, not dissimilar to our cohort $[41,42]$. The increased respiratory morbidity in infants of mothers with early onset preeclampsia in our cohort was despite the increased use of antenatal steroids.

In addition to being the first study to report on the outcomes of late preterm infants of mothers with early and late onset preeclampsia as distinct groups, there are other strengths to our study. We had a well-defined cohort from a recent era with little or no missing data and detailed demographic characteristics that affect outcomes, especially respiratory outcomes in late preterm infants. This included antenatal steroid use and chorioamnionitis, data that is missing from most studies. Importantly, our gestation was based on first trimester ultrasound or the date of embryo transfer in cases of IVF, largely limiting misclassification of gestation. In addition, health care in Canada is universal, negating the effect of socioeconomic status and differing antenatal and postnatal care on outcomes. However, there are limitations of our study. We did not investigate outcomes like intraventricular hemorrhage, bronchopulmonary dysplasia, or retinopathy of prematurity, which some studies have reported. These outcomes are, however, extremely uncommon in late preterm infants and an extremely large cohort would be needed to study them. Our population was also from single center making generalization of our results difficult. Although not the focus of the study, we did not measure any angiogenic or antiangiogenic factors in our population.

In summary we report, worse outcomes in late preterm infants of mothers with preeclampsia, which are considerably worse in infants of mothers with early onset preeclampsia as compared with late onset preeclampsia. There is uncertainty between planned immediate delivery or expectant management in women with preeclampsia between 34 and 36 weeks gestation [43]. Our data can be used to counsel mothers with preeclampsia in the late preterm period and help in identifying mothers who may benefit from delivery at facilities with higher levels of neonatal intensive care. Our results, however, need validation in a larger cohort.

Acknowledgements The authors are grateful to the Alberta Children's Hospital Research Institute for providing the funding for the study.

\section{Compliance with ethical standards}

Conflict of interest The authors declare that they have no conflict of interest.

Publisher's note Springer Nature remains neutral with regard to jurisdictional claims in published maps and institutional affiliations.

\section{References}

1. Morais M, Mehta C, Murphy K, Shah PS, Giglia L, Smith PA, et al. How often are late preterm births the result of non-evidence based practices: analysis from a retrospective cohort study at two tertiary referral centres in a nationalised healthcare system. BJOG. 2013;120:1508-14.

2. Canadian Perinatal Health Report. Public Health Agency of Canada. 2008.

3. Raju TN. The problem of late-preterm (near-term) births: a workshop summary. Pediatr Res. 2006;60:775-6.

4. Consortium on Safe Labor, Hibbard JU, Wilkins I, Sun L, Gregory $\mathrm{K}$, Haberman $\mathrm{S}$, et al. Respiratory morbidity in late preterm births. JAMA. 2010;304:419-25.

5. Teune MJ, Bakhuizen S, Gyamfi Bannerman C, Opmeer BC, van Kaam AH, van Wassenaer AG, et al. A systematic review of severe morbidity in infants born late preterm. Am J Obstet Gynecol. 2011;205:374 e371-379.

6. Mally PV, Bailey S, Hendricks-Munoz KD. Clinical issues in the management of late preterm infants. Curr Probl Pediatr Adolesc Health Care. 2010;40:218-33.

7. Johnston KM, Gooch K, Korol E, Vo P, Eyawo O, Bradt P, et al. The economic burden of prematurity in Canada. BMC Pediatr. 2014;14:93.

8. Shapiro-Mendoza CK, Tomashek KM, Kotelchuck M, Barfield W, Nannini A, Weiss J, et al. Effect of late-preterm birth and maternal medical conditions on newborn morbidity risk. Pediatrics. 2008;121:e223-232.

9. Gouyon JB, Vintejoux A, Sagot P, Burguet A, Quantin C, Ferdynus $\mathrm{C}$, et al. Neonatal outcome associated with singleton birth at 34-41 weeks of gestation. Int J Epidemiol. 2010;39:769-76.

10. Chaiworapongsa T, Chaemsaithong P, Yeo L, Romero R. Preeclampsia part 1: current understanding of its pathophysiology. Nat Rev Nephrol. 2014;10:466-80.

11. von Dadelszen P, Magee LA, Roberts JM. Subclassification of preeclampsia. Hypertens Pregnancy. 2003;22:143-8.

12. Lisonkova S, Joseph KS. Incidence of pre-eclampsia: risk factors and outcomes associated with early- versus late-onset disease. Am J Obstet Gynecol. 2013;544:e541-544.e512.

13. Lisonkova S, Sabr Y, Mayer C, Young C, Skoll A, Joseph KS. Maternal morbidity associated with early-onset and late-onset preeclampsia. Obstet Gynecol. 2014;124:771-81.

14. Stubert J, Ullmann S, Dieterich M, Diedrich D, Reimer T. Clinical differences between early- and late-onset severe preeclampsia and 
analysis of predictors for perinatal outcome. J Perinat Med. 2014;42:617-27.

15. Liu J, Wang Y, Fu W, Yang CS, Huang JJ. Diagnosis of neonatal transient tachypnea and its differentiation from respiratory distress syndrome using lung ultrasound. Medicine. 2014;93:e197.

16. Warren JB, Anderson JM. Core concepts: respiratory distress syndrome. NeoReviews. 2000;10:e351-e361.

17. Fidel-Rimon O, Shinwell ES. Respiratory distress in the term and near-term infant. NeoReviews. 2005;6:e289-e297.

18. Fenton TR, Kim JH. A systematic review and meta-analysis to revise the Fenton growth chart for preterm infants. BMC Pediatr. 2013;13:59.

19. Magee LA, Pels A, Helewa M, Rey E, von Dadelszen P.Canadian Hypertensive Disorders of Pregnancy Working Group Diagnosis, evaluation, and management of the hypertensive disorders of pregnancy. Pregnancy Hypertens. 2014;4:105-45.

20. Reilly SD, Faye-Petersen O. Chorioaminionitis and funisitis: their implications for the neonate. NeoReviews. 2008;9:e411-e417.

21. Elimian A, Figuera R, Spitzer A, Ogburn P, Wiencek V, Quirk J. Antenatal steroids: are incomplete courses beneficial. Obstet Gynecol. 2003;102:352-5.

22. Christenfeld NJ, Sloan RP, Carroll D, Greenland S. Risk factors, confounding, and the illusion of statistical control. Psychosom Med. 2004;66:868-75.

23. Derksen S, Keselman H. Backward, forward and stepwise automated subset selection algorithms: Frequency of obtaining authentic and noise variables. Br J Math Stat Psychol. 1992;45:265-82.

24. Habli M, Levine RJ, Qian C, Sibai B. Neonatal outcomes in pregnancies with preeclampsia or gestational hypertension and in normotensive pregnancies that delivered at 35,36 , or 37 weeks of gestation. Am J Obstet Gynecol. 2007;197:406 e401-407.

25. Langenveld J, Ravelli AC, van Kaam AH, van der Ham DP, van Pampus MG, Porath M, et al. Neonatal outcome of pregnancies complicated by hypertensive disorders between 34 and 37 weeks of gestation: a 7 year retrospective analysis of a national registry. Am J Obstet Gynecol. 2011;205:540.e1-7.

26. Masoura S, Kalogiannidis I, Margioula-Siarkou C, Diamanti E, Papouli M, Drossou-Agakidou V, et al. Neonatal outcomes of late preterm deliveries with pre-eclampsia. Minerva Ginecol. 2012;64:109-15.

27. Patel H, Beeby PJ, Henderson-Smart DJ. Predicting the need for ventilatory support in neonates 30-36 weeks' gestational age. J Paediatr Child Health. 2003;39:206-9.

28. Sahni R, Schiaratura M, Polin RA. Strategies for the prevention of continuous positive airway pressure failure. Semin Fetal Neonatal Med. 2016;21:196-203.

29. Kulkarni AV, Mehendale SS, Yadav HR, Kilari AS, Taralekar VS, Joshi SR. Circulating angiogenic factors and their association with birth outcomes in preeclampsia. Hypertens Res. 2010;33:561-7.

30. Staff AC, Braekke K, Harsem NK, Lyberg T, Holthe MR. Circulating concentrations of sFlt1 (soluble fms-like tyrosine kinase 1) in fetal and maternal serum during pre-eclampsia. Eur $\mathbf{J}$ Obstet Gynecol Reprod Biol. 2005;122:33-39.

31. Staff AC, Braekke K, Johnsen GM, Karumanchi SA, Harsem NK. Circulating concentrations of soluble endoglin (CD105) in fetal and maternal serum and in amniotic fluid in preeclampsia. Am J Obstet Gynecol. 2007;197:176 e171-176.

32. Wang CN, Chang SD, Peng HH, Lee YS, Chang YL, Cheng PJ, et al. Change in amniotic fluid levels of multiple antiangiogenic proteins before development of preeclampsia and intrauterine growth restriction. J Clin Endocrinol Metab. 2010;95:1431-41.

33. Thebaud B. Angiogenesis in lung development, injury and repair: implications for chronic lung disease of prematurity. Neonatology. 2007;91:291-7.

34. Chen CM, Wang LF. High-dose vascular endothelial growth factor increases surfactant protein gene expressions in preterm rat lung. Early Hum Dev. 2007;83:581-4.

35. Compernolle V, Brusselmans K, Acker T, Hoet P, Tjwa M, Beck $\mathrm{H}$, et al. Loss of HIF-2alpha and inhibition of VEGF impair fetal lung maturation, whereas treatment with VEGF prevents fatal respiratory distress in premature mice. Nat Med. 2002;8:702-10.

36. Kalay S, Cakcak B, Oztekin O, Tezel G, Tosun O, Akcakus M, et al. The role of VEGF and its soluble receptor VEGFR-1 in preterm newborns of preeclamptic mothers with RDS. J Matern Fetal Neonatal Med. 2013;26:978-83.

37. Wang A, Holston AM, Yu KF, Zhang J, Toporsian M, Karumanchi SA, et al. Circulating anti-angiogenic factors during hypertensive pregnancy and increased risk of respiratory distress syndrome in preterm neonates. J Matern Fetal Neonatal Med. 2012;25:1447-52.

38. Pinheiro CC, Rayol P, Gozzani L, Reis LM, Zampieri G, Dias CB, et al. The relationship of angiogenic factors to maternal and neonatal manifestations of early-onset and late-onset preeclampsia. Prenat Diagn. 2014;34:1084-92.

39. Schaarschmidt W, Rana S, Stepan H. The course of angiogenic factors in early- vs. late-onset preeclampsia and HELLP syndrome. J Perinat Med. 2013;41:511-6.

40. Staff AC, Harsem NK, Braekke K, Hyer M, Hoover RN, Troisi R. Maternal, gestational and neonatal characteristics and maternal angiogenic factors in normotensive pregnancies. Eur $\mathrm{J}$ Obstet Gynecol Reprod Biol. 2009;143:29-33.

41. Suga S, Yasuhi I, Aoki M, Nomiyama M, Kubo N, Kawakami K, et al. Risk factors associated with respiratory disorders in late preterm infants. J Matern Fetal Neonatal Med. 2016;29:447-51.

42. Gyamfi-Bannerman C, Gilbert S, Landon MB, Spong CY, Rouse DJ, Varner MW, et al. Effect of antenatal corticosteroids on respiratory morbidity in singletons after late-preterm birth. Obstet Gynecol. 2012;119:555-9.

43. Chappell LC, Milne F, Shennan A. Is early induction or expectant management more beneficial in women with late preterm preeclampsia? BMJ. 2015;350:h191. 